\title{
LA ACCIÓN DE DAÑO CONTINGENTE DEL ARTÍCULO 2333 del Código Civil CHILENO: SUS Elementos Y ÁMBITO DE APLICACIÓN*
}

[The contingent damages action in the art. 2333 of Chilean Civil Code: its elements and scope of applicability]

\author{
José Luis Díez Schwerter** \\ Universidad de Concepción (Chile)
}

\section{RESUMEN}

En esta investigación se analizan los principales elementos de la original acción general por daño contingente que Andrés Bello incorporó en el art. 2333 del Código Civil chileno, a objeto de fijar consecuentemente su ámbito de aplicación. Se examina la doctrina atingente y los escasos fallos referidos a la materia, destacando que su uso práctico permitiría a la responsabilidad civil cumplir en

\section{ABSTRACT}

This paper will analyze the main elements of the original action for contingent damages, that Andrés Bello wrote into article 2333 of the Chilean Civil Code, in order to properly determine its correct application. Relevant doctrine and the meager case law produced are analyzed, concluding that its use would allow civil liability to fulfill an effective and direct preventive role, which would

RECIBIDO el 15 de marzo y ACEPTADO el 20 de mayo de 2016

* Este trabajo forma parte del proyecto de investigación FONDECYT (regular 2014) No 1140525 , titulado "La acción preventiva por daño contingente contemplada en el artículo 2333 del Código Civil: análisis crítico de sus elementos constitutivos y propuestas sobre su ámbito de aplicación”, del que el autor es el investigador responsable.

** Profesor de Derecho civil de la Facultad de Ciencias Jurídicas y Sociales de la Universidad de Concepción. Dirección postal: Facultad de Ciencias Jurídicas y Sociales, Universidad de Concepción, Barrio Universitario s/n, Casilla 160-C, Correo 3, Concepción, Chile. Correo electrónico: jdiez@udec.cl 
forma efectiva una función preventiva directa, que coexiste con la tradicional función reparatoria.

\section{Palabras Clave}

Responsabilidad extracontractual (Chile) - Daño contingente - Acción popular - Prevención del daño. coexist with its traditional reparatory function..

KeYwords
Chilean Tort Law - Contingent
damage - Popular Action - Damages
prevention.

KEYWORDS prevention.

\section{INTRODUCCIÓN}

El Código Civil chileno consagra una acción por daño contingente en su artículo 2333, señalando al efecto: "Por regla general, se concede acción popular en todos los casos de daño contingente que por imprudencia o negligencia de alguien amenace a personas indeterminadas; pero si el daño amenazare solamente a personas determinadas, solo alguna de éstas podrá intentar la acción".

Como hemos señalado anteriormente, se trata de una innovación de Andrés Bello ${ }^{1}$, quien además buscó incentivar su ejercicio, al establecer en el artículo 2334: "Si las acciones populares a que dan derecho los artículos precedentes, parecieren fundadas, será el actor indemnizado de todas las costas de la acción, y se le pagará lo que valgan el tiempo y diligencia empleados en ella, sin perjuicio de la remuneración específica que conceda la ley en casos determinados".

El presente trabajo tiene por objeto identificar y profundizar en los diversos elementos que configuran dicha acción, lo que consecuencialmente servirá para fijar su ámbito de aplicación.

Para ello tendremos presente las (aún escasas) sentencias dictadas sobre el particular ${ }^{2}$, así como las opiniones doctrinarias vertidas sobre el punto,

${ }^{1}$ V. Díez Schwerter, José Luis y Delgado Schneider, Verónica, Algunas útiles herramientas olvidadas en nuestra práctica del Derecho de Daños, en Revista de Derecho Universidad de Concepción (Chile), 214, 2003 [pero 2005], p. 144.

${ }^{2}$ Al respecto v.: Corte Suprema, 13 de septiembre de 1913, en Revista de Derecho y Jurisprudencia, T. 12, sec. $1^{\text {a }}$, p. 68 ss.; sentencia de $17^{\mathrm{o}}$ Juzgado Civil de Santiago, 26 de agosto de 2003, en causa Rol 2525-1999, dictada por Jueza Inelie Durán Madina, caratulada "Moreno con Plásticos", confirmada por la Corte de Apelaciones de Santiago, en sentencia de 9 de agosto de 2012, en causa Rol 1452-2004 y rechazándose recursos de casación en la forma en sentencia de la Corte Suprema de 16 de noviembre de 2012, en causa Rol 7724-2012; sentencia del $2^{\circ}$ Juzgado de Letras en lo Civil de Concepción, de 16 de octubre de 2006, dictada por el Juez Ti- 
contenidas en obras generales sobre responsabilidad extracontractual ${ }^{3}$ y en puntuales estudios específicos sobre esta acción ${ }^{4}$.

Cabe anotar finalmente que la acción por daño contingente está presente también en Ecuador, Colombia y El Salvador, producto de la adopción del Código Civil chileno en esos países, teniendo ahí sus propios desarrollos, como hemos expuesto en otra sede ${ }^{5}$.

tular don Camilo Álvarez Órdenes, en causa Rol 1675-2006, caratulada “Sepúlveda Torres y otros con Servicio de la Vivienda y Urbanización Octava Región del Bío Bío"; sentencia del $3^{\circ}$ Juzgado de Letras en lo Civil de Concepción, de 28 de abril de 2008, dictada por doña Carola Paz Rivas Vargas, Juez Titular, en causa Rol 21132008 (acumulada Rol 2796-2008) caratulada “Álvarez con Empresa de Ferrocarriles del Estado", confirmada por Corte de Apelaciones de Concepción, en sentencia de 25 de enero de 2011, Rol 317-2010, redacción del Abogado Integrante don Gonzalo Cortez Matcovich; sentencia del $13^{\circ}$ Juzgado Civil de Santiago, de 22 de julio de 2014, Rol 6954-2012, dictada por doña Nancy Torrealba Pérez, Juez subrogante caratulada "Sociedad Concesionaria Rutas del Pacífico S.A. con Sociedad Agrícola ARC Holding Ltda.”, revocada por Corte de Apelaciones de Santiago, en sentencia de 27 de febrero de 2015, en causa Rol 7396-2014; y sentencia del Juzgado de Letras de Cauquenes, de 6 de febrero de 2016, dictada por don Carlos Gajardo Ortiz, Juez Titular en causa Rol 774-2013, caratulada, "Amaya con Leal”.

3 Alessandri Rodríguez, Arturo, De la responsabilidad extracontractual en el Derecho Civil chileno (Santiago, Imprenta Universitaria, 1943), pp. 218 a 220; BARROS Bourie, Enrique, Tratado de responsabilidad extracontractual (Santiago, Editorial Jurídica de Chile, 2006), pp. 795 y 941; Corral TALCIAnI, Hernán, Lecciones de responsabilidad civil extracontractual (segunda edición, Santiago, Thomson Reuters, 2013), pp. 409 a 415; Rodríguez Grez, Pablo, Responsabilidad extracontractual (Santiago, Editorial Jurídica de Chile, 1999), pp. 284-289; TAPIA SuÁreZ, Orlando, De la responsabilidad civil en general y de la responsabilidad delictual entre los contratantes, Memoria de Prueba, Publicaciones del Seminario de Derecho Privado de la Facultad de Ciencias Jurídicas y Sociales de la Universidad de Concepción (Escuela Tipográfica Salesiana, Concepción, 1941), existiendo reimpresión el año 2006, publicada por la Editorial LexisNexis, tratando esta materia en pp. 197 y 198, a la cual estarán referidas las citas que se hagan en este artículo.

${ }^{4}$ Diez Schwerter - Delgado Schneider, cit. (n. 1); Diez Schwerter, José Luis, Notas sobre la acción preventiva de daños del artículo 2333 del Código Civil: a propósito de un fallo reciente, en Revista de Derecho Universidad de Concepción (Chile), 217-218, 2005 [pero 2006], pp. 317-321; Molinari VALDÉs, Aldo, De la responsabilidad civil al derecho de daños y tutela preventiva civil (Santiago, LexisNexis, 2004); PINO Silva, Néstor, Responsabilidad preventiva, en Revista de Estudios Ius Novum (Chile), 2, 2009, pp. 243-267.

${ }^{5}$ V. Diez SCHWerter, José Luis, La aplicación de la acción por daño contingente en Chile, Colombia y Ecuador: del modelo de Bello a nuestros días, en Revista de Derecho Privado, Universidad Externado de Colombia, 2016, volumen 30, en prensa. 


\section{Elementos DE LA ACCiÓN DE DAÑO CONTINGENTE Y SU} APLICACIÓN JURISPRUDENCIAL

\section{El carácter "contingente" del daño}

Para que opere la acción del artículo 2333 se requiere, en primer término, que estemos en presencia de un daño contingente, es decir, "que puede suceder o no suceder", según entiende por "contingente" el Diccionario de la Real Academia Española de la Lengua.

De este modo, si se trata de daños ya inferidos (al estar consumados o al ser daños futuros inevitables), no operará la acción que establece el art. 2333 sino la acción reparatoria, in natura o a través de un equivalente, sea o no dinerario, en base a la cláusula general del artículo 2314 del CC (que se refiere precisamente al daño "inferido"), habiéndose resuelto así que no es posible acoger una demanda en lo relativo al daño contingente si en verdad se trata de un perjuicio que "ya se produjo".

En todo caso, una misma situación puede generar tanto acciones reparatorias como la preventiva establecida en el artículo 2333, si junto a daños ya inferidos genera también daños contingentes de los que fundadamente se pueda temer ${ }^{7}$. En tal caso los legitimados activos podrían no coincidir, pues los presupuestos de dichas acciones son diversos, sin perjuicio que el artículo 2333 concede acción popular si el daño contingente amenaza a personas indeterminadas 8 .

${ }^{6}$ Sentencia del $2^{\circ}$ Juzgado Civil de Temuco, de 24 de marzo de 2012, Rol 2445- 2011, dictada por doña Mónica Toledo Reyne, Juez subrogante, caratulada "Gacitúa con Municipalidad de Temuco", considerando $11^{\circ}$, y en el mismo sentido: sentencia del $1^{\circ}$ Juzgado Civil de Temuco, 18 de enero de 2016, en causa Rol 56752014, dictada por don Javier Bascur Pavéz, Juez Suplente, caratulada "Vega con Municipalidad de Temuco", considerando $13^{\circ}$. Se trata de situaciones singulares, pues en ambos casos los actores solicitaron una indemnización pecuniaria por daño contingente, la que fue rechazada por la razón indicada.

$7 \mathrm{Al}$ efecto ejerciendo en una misma demanda acción indemnizatoria y acción por daño contingente del artículo 2333 del Código Civil, véase: sentencia del $17^{\circ}$ Juzgado Civil de Santiago, de 26 de agosto de 2003, dictada por Inelie Durán Madina, Juez, en causa Rol 2525-1999, caratulada "Moreno con Plásticos", confirmada por la Corte de Apelaciones de Santiago, en sentencia de 9 de agosto de 2012, en causa Rol 1452-2004 y rechazándose recursos de casación en la forma y fondo, en sentencia de la Corte Suprema de 16 de noviembre de 2012, en causa Rol 77242012. En este caso se rechaza la demanda al establecerse que "las supuestas conductas desleales denunciadas por la parte demandante no son efectivas".

${ }^{8}$ En esta misma línea en derecho colombiano se ha observado que "la indemnización del daño pasado sólo podrá ser reclamada por la víctima directa y determinada; en tanto que la supresión de la causa productora del daño, amenaza de daño contingente, puede ser demandada por cualquier persona, si la conducta del responsable, 
Subyace así, también en el Título XXXV del Libro IV del CC, la distinción entre "daño sufrido" o "recibido" y "daño temido", que el mencionado código utiliza y explicita en materia de acciones posesorias e interdictos especiales?.

2. La exigencia de "amenaza" a personas determinadas o indeterminadas

Para que proceda la acción del artículo 2333 se requiere adicionalmente que el daño contingente "amenace" a personas determinadas o indeterminadas. Ello implica, a nuestro entender, que deben existir indicios de estar inminente dicho daño ${ }^{10}$, capaces de producir un justo motivo de temerlo ${ }^{11}$. En tal sentido, la doctrina y jurisprudencia nacionales, exigen una "inminencia clara y probada" 12 , una "probabilidad razonable y concreta" 13 , una "posibilidad o peligro inminente"14, un "riesgo actual,

además de afectar a personas determinadas, afecta también a toda la colectividad" (Tamayo Jaramillo, Javier, De la responsabilidad civil, (Santa Fe de Bogotá, Ed. Temis, 1986), T. II (De los perjuicios y su indemnización), p. 80.

${ }^{9} \mathrm{Al}$ respecto en materia posesoria y de interdictos especiales: art. 921 distinguiendo entre el daño "recibido" y el que "fundadamente" se "teme"; y art. 946 inciso 10 "...pero la indemnización a que por los daños recibidos hubiere lugar..."; e inciso $2^{\circ}$ : "Y si el daño sufrido o temido...".

Por su parte el Título XXXV del Libro IV, el CC. se refiere, por un lado, al daño "inferido", "sufrido" o que se "hizo" (art. 2314: "El que ha cometido un delito o cuasidelito que ha inferido daño a otro, está obligado a la indemnización..."; art. 2315: "Puede pedir esta indemnización no sólo el que es dueño o poseedor de la cosa que ha sufrido el daño..."; art. 2316: "Están obligados a la indemnización el que hizo el daño..."); en tanto que en el art. 2333 trata del "daño contingente" que "amenace" o "amenazare" a personas indeterminadas o determinadas; y previamente el art. 2328 inc. $1^{\circ}$ alude al "daño causado por una cosa que cae o se arroja de la parte superior de un edificio...", y en el inc. $2^{\circ}$ establece que "Si hubiere alguna cosa que, de la parte superior de un edificio o de otro paraje elevado, amenace caída y daño...”.

${ }_{10}$ Teniendo presente para ello que el Diccionario de la Real Academia Española entiende por "amenazar" el "dar indicios de estar inminente alguna cosa mala o desagradable".

${ }^{11}$ Utilizando la expresión contenida en el artículo 950 inciso $2^{\circ}$ CC., el cual en materia de acciones posesorias especiales, establece que: "las dirigidas a precaver un daño no prescriben mientras haya justo motivo de temerlo", finalidad que precisamente busca la acción del art. 2333 del CC.

${ }^{12}$ Corral Talciani, Lecciones, cit. (n. 3), p. 409. Lo sostenido por este autor es citado a su vez por la Corte de Apelaciones de Concepción en sentencia de 25 de enero de 2011, Rol 317-2010, caratulada "Álvarez con Empresa de Ferrocarriles del Estado", considerando 6 ${ }^{\circ}$, redacción del Abogado Integrante don Gonzalo Cortez Matcovich.

${ }^{13}$ Sentencia del $3^{\circ}$ Juzgado Civil de Concepción, de 21 de enero de 2015, Rol 7114-2012, dictada por don Carlos Alejandro Hidalgo Muñoz, Juez titular, caratulada "Florio con Himce Ltda", considerando 15.

${ }^{14}$ Molinari Valdés, cit. (n. 4), pp. 204 y 205, citado a su vez por Corte de 
real y comprobable"15, una "situación de peligro de la cual puede derivarse razonablemente un daño resarcible (riesgo)" 16 si no se imponen medidas destinadas a precaverlo. Como bien expresa Corral Talciani, no basta entonces que el daño sea "meramente hipotético o posible, es necesario que sea más que probable"17.

Ahora bien, determinar si estamos en presencia de un daño contingente, en los términos vistos es una cuestión de hecho que establecen los jueces del fondo ${ }^{18}$, quienes para ello deberán considerar objetivamente la situación concreta en base a los antecedentes que obren en el pleito. Al efecto, se han acogido demandas de este tipo luego de establecerse que "en las condiciones que se encuentra el inmueble [sitio no cercado, con escombros, basuras y en cuyas inmediaciones existen algunas casas] tal como lo reconoce la demandada, existe una amenaza clara que, en el evento de permanecer en la situación en que se halla el bien raíz, ocurrirá el perjuicio que se trata

Apelaciones de Santiago, sentencia de 27 de febrero de 2015, Rol 7396-2014, caratulada "Sociedad Concesionaria Rutas del Pacífico S.A. con Sociedad Agrícola ARC Holding Ltda.”, redacción de la ministra señora Jessica González Troncoso, considerando $3^{\circ}$.

15 Sentencia del $13^{\circ}$ Juzgado Civil de Santiago, de 22 de julio de 2014, dictada por doña Nancy Torrealba Pérez, Juez subrogante, Rol 6954-2012, caratulada "Sociedad Concesionaria Rutas del Pacífico S.A. con Sociedad Agrícola ARC Holding Ltda.", considerando $21^{\circ}$ (sentencia que en todo caso fue revocada por Corte de Apelaciones de Santiago, en sentencia de 27 de febrero de 2015, Rol 7396-2014, redacción de la ministra señora Jessica González Troncoso, acogiéndose en definitiva demanda de daño contingente del artículo 2333).

${ }^{16}$ Rodríguez Grez, Pablo, cit. (n. 3), p. 285, citado a su vez por sentencia del $2^{\circ}$ Juzgado de Letras en lo Civil de Concepción, de 16 de octubre de 2006, Rol 1675-2006, dictada por el Juez Titular don Camilo Álvarez Órdenes, caratulada "Sepúlveda Torres y otros con Servicio de la Vivienda y Urbanización Octava Región del Bío Bío", considerando 6º y en sentencia del $13^{\circ}$ Juzgado Civil de Santiago, de 22 de julio de 2014, dictada por doña Nancy Torrealba Pérez, Juez subrogante, Rol 6954-2012, caratulada "Sociedad Concesionaria Rutas del Pacífico S.A. con Sociedad Agrícola ARC Holding Ltda.", considerando $20^{\circ}$.

${ }^{17}$ Corral Talciani, Lecciones, cit. (n. 3), p. 409, opinión que a su vez es citada en: Corte de Apelaciones de Concepción, sentencia de 25 de enero de 2011, Rol 317-2010, caratulada "Álvarez con Empresa de Ferrocarriles del Estado", redacción del Abogado Integrante don Gonzalo Cortez Matcovich, considerando 6o.

${ }^{18}$ En tal sentido: Barros Bourie, Tratado, cit. (n. 3), p. 874; Tapia SuÁrez, cit. (n. 3), p. 198.

$\mathrm{Y}$ al efecto se ha fallado en sede de casación en el fondo que no pueden considerarse infringidos los artículo 2333 y 2334 del Código Civil desde que "los jueces del fondo no han dado por establecido que la construcción de la muralla D. E. amenace daño" (Corte Suprema, 13 de septiembre de 1913, en Revista de Derecho y Jurisprudencia, 12 , sec. $1^{\mathrm{a}}$, p. 68 ss., considerando $\left.4^{\mathrm{o}}\right)$. 
de evitar a través del ejercicio de la acción entablada constituido por un daño contingente a la integridad física y psíquica de los demandantes, en cuanto actores populares" 19 ; o que "no puede sino concluirse la existencia de una amenaza clara en cuanto a que de continuar utilizándose -en los días de bajas temperaturas- múltiples y dispersos focos de fuego en lugares estratégicos del Fundo Tapihue, para prevenir daños en los viñedos, puede razonablemente provocarse el perjuicio que se busca evitar, esto es, colisiones por falta de visibilidad en los conductores usuarios de la Ruta 68, daño contingente que por cierto afectaría la integridad física de éstos. Se trata de un daño futuro que bajo condiciones climáticas adversas, como ya aconteció el 12 de octubre de 2011, se torna cierto y predecible, pues representa una probabilidad concreta de que el daño se produzca, esto es, existe una convicción razonada y lógica de que sucederá y, por tanto, se verifica en este escenario fáctico la necesaria vinculación entre el daño que se pretende evitar y la conducta infractora acreditada" ${ }^{\text {. }}$.

A la inversa, en tanto, se rechazará la demanda por daño contingente si "no ha podido acreditarse en autos la vulneración por parte de la demandada [Empresa de Ferrocarriles del Estado] a las medidas de seguridad que está obligada a implementar en el cruce Diagonal Bío Bío, y que ellas pongan en peligro la seguridad de los usuarios del cruce ferroviario" 21 , añadiéndose en sede de apelación que "resulta insuficiente para que se configure el daño contingente, la situación de riesgo general ocasionada por actividades que, en sí mismas, resultan potencialmente lesivas para las personas, como el transporte ferroviario"22.

Útil es tener presente, en este punto, el desarrollo que al concepto de amenaza se ha dado en materia de recurso de protección, donde un elevado número de acciones se han deducido denunciando amenazas a los

${ }^{19}$ Sentencia del $2^{\circ}$ Juzgado de Letras en lo Civil de Concepción, de 16 de octubre de 2006, dictada por el Juez Titular don Camilo Álvarez Órdenes, Rol 16752006, caratulados "Sepúlveda Torres y otros con Servicio de la Vivienda y Urbanización Octava Región del Bío Bío”, considerando 7º.

${ }^{20}$ Corte de Apelaciones de Santiago, sentencia de 27 de febrero de 2015, Rol 7396-2014, caratulada "Sociedad Concesionaria Rutas del Pacífico S.A. con Sociedad Agrícola ARC Holding Ltda.”, redacción de la ministra señora Jessica González Troncoso, considerando $10^{\circ}$.

${ }^{21}$ Sentencia de 28 de abril de 2008, $3^{\circ}$ Juzgado de Letras en lo Civil de Concepción, dictada por doña Carola Paz Rivas Vargas, Juez Titular, Rol 2113-2008 (acumulada Rol 2796-2008) caratulada "Álvarez con Empresa de Ferrocarriles del Estado", considerando $18^{\circ}$.

${ }^{22}$ Corte de Apelaciones de Concepción, sentencia de 25 de enero de 2011, Rol 317-2010, caratulada "Álvarez con Empresa de Ferrocarriles del Estado", redacción del Abogado Integrante don Gonzalo Cortez Matcovich, considerando 6º. 
derechos señalados en el artículo 20 de la Constitución y a fin de impedir su consumación, entendiéndose que aquélla representa "un peligro inminente, cierto y actual de que el hecho nocivo pueda efectivamente ocurrir en el tiempo próximo"23.

\section{Naturaleza del daño contingente}

El daño que amenaza con producirse puede ser de cualquiera naturale$\mathrm{za}^{24}$, pues el art. 2333 - lejos de efectuar distinciones o exclusiones - declara expresamente que opera "por regla general, en todos los casos de daño contingente", teniendo entonces un vasto ámbito de aplicación, aunque el

${ }^{23}$ Corte Suprema, sentencia de 26 de enero de 2009, Rol 7562-2008, caratulada "Manuel Pérez Sánchez y otros con Empresa Inmobiliaria Puerto Brandt S.A.", redacción del Ministro señor Adalis Oyarzún Miranda, considerando 3º

Siendo recurrentes las citas a la noción dada por Soto KLOss, Eduardo ( $E l$ Recurso de Protección, Santiago, Editorial Jurídica de Chile, 1982, p. 85), para quien amenaza implica un "peligro de suceder algún mal; indicio de sobrevenir de modo inminente algo malo o desagradable; presagio de hacer temer un mal; palabra, gesto o acto por medio del cual se expresa la voluntad de querer hacer mal a alguien, anuncio de un mal futuro, etc." (Corte de Apelaciones de Concepción, sentencia de 24 de abril de 2006, Rol 2443-2005, caratulada "Jacqueline Van Rysselberghe Herrera con Empresa de Servicios Sanitarios del Bío Bío S.A. ESSBIO y otra”, redacción de la Ministro doña Sara Victoria Herrera Merino, considerando $10^{\circ}$. En el mismo sentido se pronuncia: Corte de Apelaciones de Antofagasta, sentencia de 6 de octubre de 2008, Rol 495-2008, caratulada "Aguas Antofagasta S.A. contra Sociedad Desalant S.A.”, redacción de la Ministro doña Gabriela Soto Chandía, considerando 5\%; Corte de Apelaciones de Coyhaique, sentencia de 3 de abril de 2014, Rol 562013, caratulada "Corporación Fiscalía del Medio Ambiente contra Comisión de Evaluación Ambiental del Servicio de Evaluación Ambiental de la región de Aysén”, redacción del ministro señor Luis Daniel Sepúlveda Coronado, considerando 33º). Y recordándose además que según el mencionado autor la amenaza "requiere que sea cierta, lo que conlleva a que sea actual, contemporánea al momento de recurrirse de protección; y además, debe ser precisa en su formulación y no vaga, de modo que el juez pueda determinar si es antijurídica o no en sus extremos" (Corte de Apelaciones de Valdivia, sentencia de 27 de enero de 2009, Rol 845-2008, caratulada "Riesco B. Vladimir con Com. Medio Ambiente Región de Los Ríos”, redacción de la Ministro doña Ruby Antonia Alvear Miranda, considerando 13ㅇ).

${ }^{24}$ En tal sentido: Corral Talciani, Lecciones, cit. (n. 3), p. 410. En la jurisprudencia se ha resuelto que "el interés que da lugar a la acción, sería la protección del derecho a la integridad física, a la salud o propiedad de los sujetos de la comunidad”, sentencia del $13^{\circ}$ Juzgado Civil de Santiago, de 22 de julio de 2014, dictada por doña Nancy Torrealba Pérez, Juez subrogante, Rol 6954-2012, caratulada "Sociedad Concesionaria Rutas del Pacífico S.A. con Sociedad Agrícola ARC Holding Ltda.”, considerando $20^{\circ}$, sentencia que en todo caso fue revocada por Corte de Apelaciones de Santiago, en sentencia de 27 de febrero de 2015, Rol 7396-2014. 
daño temido deberá cumplir con los caracteres de ilicitud y anormalidad propios del daño extracontractual ${ }^{25}$.

En todo caso, a nuestro entender constituye desde ya un daño material reparable la desvalorización que en bienes ajenos pueda generar la presencia de un daño contingente ${ }^{26}$, así como los gastos razonables realizados para evitar un daño que amenaza con producirse ${ }^{27}$; e implicará un daño moral resarcible el dolor, sufrimiento y alteración de las condiciones normales de vida que el daño contingente pueda provocar en el amenazado.

\section{Criterio de imputación}

La acción por daño contingente que consagra el artículo 2333 del CC parte del supuesto que dicho daño derive de "imprudencia o negligencia de alguien" 28 .

Y, aunque no lo exprese la norma creemos que -con mayor razónprocederá dicha acción si la amenaza de daño deriva de dolo ajeno ${ }^{29}$.

Tanto las conductas representativas de dolo o de culpa podrán ser acciones u omisiones. La disposición no distingue.

Y en principio tales criterios de imputación deberán ser probados por el actor al ser presupuestos de la obligación de prevenir que sostiene (art. 1698), sin perjuicio que por incumplirse precisos deberes de cuidado y diligencia que el legislador $\mathrm{u}$ otras autoridades con potestad normativa hayan impuesto, se dé por establecida la llamada "culpa contra la legalidad"30.

${ }^{25} \mathrm{Al}$ efecto se ha indicado que la acción del artículo 2333 del CC no alcanza "las hipótesis en que el daño se debe a los riesgos que debemos tolerar por el hecho de vivir en sociedad" (Barros Bourie, Enrique, Tratado, cit. (n. 3), p. 874, citado a su vez por la Corte de Apelaciones de Concepción, sentencia de 25 de enero de 2011, Rol 317-2010, caratulada "Álvarez con Empresa de Ferrocarriles del Estado", redacción del Abogado Integrante don Gonzalo Cortez Matcovich, considerando 6o).

${ }^{26}$ Así lo sostuvimos en: Diez Schwerter, José Luis, El daño extracontractual. Jurisprudencia y doctrina (Santiago, Editorial Jurídica de Chile, 1997), p. 71, siguiendo a Zannoni y De Cupis.

${ }^{27}$ Así, por lo demás, se establece expresamente en los "Principios de derecho europeo de la responsabilidad civil" (Art. 2:104, sobre "Gastos preventivos"). Y como fue planteado en al menos un caso en nuestro país (sentencia del $3^{\circ}$ Juzgado Civil de Concepción, de 21 de enero de 2015, dictada por don Carlos Alejandro Hidalgo Muñoz, Juez titular, Rol 7114-2012, caratulada "Florio con Himce Ltda", donde en todo caso se rechaza la petición al establecerse que, con la intención de evitar el daño contingente, el actor incurrió en actos de autotutela.

${ }_{28}$ Aunque la exigencia de culpa ha sido criticada y denunciada como un "resabio del sistema de responsabilidad civil, incompatible con el amparo anticipatorio" (Molinari Valdés, cit. (n. 4), pp. 215 a 217).

${ }^{29}$ En tal sentido, Corral Talciani, Lecciones, cit. (n. 3), p. 410.

${ }^{30} \mathrm{Al}$ efecto se ha resuelto que "para prevenir los daños, la ley y los reglamentos 
Cabe hacer presente que el diseño original de esta institución contenido en el Proyecto de Código Civil de 1846-1847 no contemplaba expresamente esta exigencia subjetiva ${ }^{31}$, la que fue introducida en el Proyecto de 1853 que fijó la redacción definitiva de la regla ${ }^{32}$.

En cuanto al estándar de culpa exigible en esta materia creemos que es el de la culpa leve, desde que el artículo 44 del CC dispone que "culpa o descuido sin otra denominación es culpa o descuido leve", y ello es precisamente lo que acontece en esta norma en que se alude a la "imprudencia o negligencia de alguien" sin fijar un grado específico por el que se responda ${ }^{33}$. De este modo, no compartimos lo sostenido en una antigua sentencia de la Corte Suprema que exigió que la imprudencia o negligencia hayan sido "temerarias" 34 .

En base a lo expuesto, cabe concluir que es improcedente la acción por daño contingente del artículo 2333 del CC si éste emana de un hecho de la naturaleza o de una conducta ajena a la cual no pueda atribuírsele culpa ni dolo ${ }^{35}$, sin perjuicio que pudieran concurrir a su respecto otras

prescriben o prohíben determinados actos. Dado que se reputa que esos cuerpos legales son conocidos por todos, su inobservancia constituye culpa" (Corte de Apelaciones de Santiago, 17 de abril de 2002, en Gaceta Jurídica No 262, p. 81 ss., considerando $20^{\circ}$, con cita a Planiol y Ripert).

31 Proyecto de CC de 1846/1847: artículo 671: "Las acciones populares concedidas en el presente título tendrán cabida en todos los casos de daño continjente [sic] que amenace a personas indeterminadas; pero, si el daño amenazare solamente a personas determinadas, solo alguna de éstas podrá intentar la acción".

32 Proyecto de CC de 1853: artículo 2497: "Por regla general, se concede acción popular en todos los casos de daño continjente, que por imprudencia o neglijencia de alguien amenace a personas indeterminadas; pero, si el daño amenazare solamente a personas determinadas, solo alguna de éstas podrá intentar la acción”.

33 Además ha de tenerse presente que existe una fuerte tendencia que sostiene que en general en materia extracontractual se respondería hasta de culpa leve; al efecto, en doctrina: Barros Bourie, Enrique, Tratado, cit. (n. 3), pp. 81 y 82; DieZ SCHWERTER, El daño extracontractual, cit. (n. 26), p. 162, nota 55; LARroucau ToRRES, Jorge, La culpa y el dolo en la responsabilidad extracontractual. Análisis jurisprudencial, Memoria de Prueba, Fondo de Publicaciones, Facultad de Ciencias Jurídicas y Sociales, Universidad de Concepción, 2005, pp. 129-133; Meza Barros, Ramón, Manual de Derecho Civil. De las fuentes de las obligaciones (9a edición, actualizada por Pedro Pablo Vergara, Santiago, Editorial Jurídica de Chile, 1997), T. II, p. 263. Y en la jurisprudencia: Corte Suprema, 21 de junio de 1941, en RDJ. 39 (Santiago, 1942), $2^{a}$ parte, sección $1^{\mathrm{a}}$, p. 79, considerando $8^{\mathrm{o}}$; y Corte de Apelaciones de Santiago, 18 de octubre de 1956, en RDJ. 53 (Santiago, 1956), 2a parte, sección $4^{\mathrm{a}}$, p. 138 , considerando $5^{\circ}$.

${ }^{34}$ Corte Suprema, 13 de septiembre de 1913, en $R D J .12$, sec. $1^{\text {a }}$, p. 68 ss., considerando $4^{\circ}$.

${ }^{35} \mathrm{Al}$ efecto se ha resuelto que debe rechazarse la demanda si los jueces de fon- 
acciones dirigidas a precaver daños que no exijan esos factores de imputación subjetivos ${ }^{36}$.

\section{Sujeto pasivo}

El artículo 2333 del CC concede acción en todos los casos de daño contingente que por imprudencia o negligencia "de alguien" amenace a personas determinadas o indeterminadas, pudiendo accionarse así en contra de personas naturales o jurídicas ${ }^{37}$, públicas o privadas ${ }^{38}$, pues el Código no efectúa exclusiones.

En todo caso, debe tenerse presente que como la acción del artículo

do "no han dado por establecido que la construcción de la muralla D. E. amenace daño, ni tampoco que haya habido imprudencia o negligencia temeraria que importe un cuasi-delito, que diera derecho a la recurrente para reclamar perjuicios" (Corte Suprema, 13 de septiembre de 1913, en RDJ. 12, sec. 1a, p. 68 ss.); o si se ha acreditado "que las supuestas conductas desleales denunciadas por la parte demandante no son efectivas" (Sentencia del 17º Juzgado Civil de Santiago, de 26 de agosto de 2003, dictada por Juez Inelie Durán Madina, en causa Rol 2525-1999, caratulada "Moreno con Plásticos", confirmada por la Corte de Apelaciones de Santiago, en sentencia de 9 de agosto de 2012, en causa Rol 1452-2004 y rechazándose recursos de casación en la forma y en sentencia de la Corte Suprema de 16 de noviembre de 2012, en causa Rol 7724-2012); o si "no ha podido acreditarse en autos la vulneración por parte de la demandada [Empresa de Ferrocarriles del Estado] a las medidas de seguridad que está obligada a implementar en el cruce Diagonal Bio Bio, y que ellas pongan en peligro la seguridad de los usuarios del cruce ferroviario" (Sentencia del $3^{\circ}$ Juzgado de Letras en lo Civil de Concepción, de 28 de abril de 2008, dictada por doña Carola Paz Rivas Vargas, Juez Titular, en causa Rol 21132008 (acumulada Rol 2796-2008) caratulada "Álvarez con Empresa de Ferrocarriles del Estado", considerando $18^{\circ}$ ); o si se constata que la causa ejecutiva que los actores intentaban detener por medio de la acción de daño contingente del art. 2333 estaba "debidamente tramitada en forma y fondo" (Sentencia del Juzgado de Letras de Cauquenes, de 6 de febrero de 2016, dictada por don Carlos Gajardo Ortiz, Juez Titular, en causa Rol 774-2013, caratulada, “Amaya con Leal”, considerando 15\%).

${ }^{36}$ Como sucede en materia extracontractual en el artículo 2328 inciso $2^{\circ}$; en materia de servidumbres en los artículos 855 y 856 ; en materia de acciones posesorias e interdictos especiales en los artículos 930, 932, 935 y 941; en materia sucesoria, en el artículo 1378; y en materia contractual en el artículo 1496, reglas que establecen herramientas preventivas que no exigen un criterio de imputación subjetivo para que sean procedentes y que hemos individualizado en nuestro derecho siguiendo el muy original trabajo realizado en Colombia por Restrepo Rodríguez, Tomás, El remedio preventivo en la responsabilidad civil, en Revista de Derecho Privado Universidad Externado de Colombia, $\mathrm{N}^{\circ}$ 14, 2008, Colombia, pp. 219 a 238, con alusiones a los artículos correspondientes del Código Civil colombiano.

${ }^{37}$ Corral Talciani, Lecciones, cit. (n. 3), p. 411.

38 Así, Sarmiento Palacio, Germán, Las acciones populares en el Derecho Privado Colombiano (reimpresión de la primera edición de 1988, Bogotá, Editorial Universi- 
2333 tiene por finalidad precaver un daño contingente el legitimado pasivo deberá ser alguien que actualmente esté en condiciones de prevenirlo (por sí o mediante la acción de terceros en su nombre).

Así las cosas, si por culpa o dolo de alguien se genera y se mantiene una amenaza de daño se dirigirá en su contra la acción del artículo 2333 pues él podría diligentemente hacerla desaparecer.

Pero si quien generó la amenaza de daño por su culpa o dolo pierde luego el control de la situación de donde ella emana será inoficioso demandarlo por esta acción pues le será imposible cumplir una eventual sentencia condenatoria, que tiene fines preventivos (sin perjuicio de su eventual responsabilidad reparatoria si el daño se consuma ${ }^{39}$. En tal caso, lo pertinente será que la acción del artículo 2333 se dirija en contra de quien teniendo el control actual de la situación de donde surge la amenaza de daño culposa o dolosamente no la elimina.

\section{Sujeto activo}

Al respecto el artículo 2333 del CC resuelve el punto distinguiendo si el daño contingente amenaza a personas determinadas o indeterminadas.

En el primer caso concede "acción popular", lo que implica que podrá accionar "cualquier persona del pueblo" 40 en defensa del interés público ${ }^{41}$,

dad del Rosario, 2006), p. 10, analizando el artículo 2359 del Código Civil colombiano.

${ }^{39}$ Lo dicho en todo caso no permite descartar su eventual responsabilidad reparatoria si el daño llega a consumarse, la que, según el caso, podría operar sin perjuicio de la que pueda tener quien lo haya sucedido en la administración de la fuente de la amenaza.

${ }^{40} \mathrm{Al}$ efecto, indicativo resulta el artículo 2334 del Código Civil el cual al establecer recompensas económicas para el caso que "las acciones populares a que dan derecho los artículos precedentes parecieren fundadas" se está refiriendo tanto a la concedida expresamente como "acción popular" en el artículo 2333 como a la otorgada a "cualquiera persona del pueblo" en el 2328 inciso $2^{\circ}$, la cual es una acción de ese tipo aunque no se la califique expresamente como tal.

Y lo mismo puede concluirse al relacionar los artículos 948 y 949 del Código Civil. Al efecto, el primero otorga legitimación a la "municipalidad y cualquiera persona del pueblo" en favor "de los caminos, plazas u otros lugares de uso público, y para la seguridad de los que transitan por ellos", en tanto que el artículo 949 se refiere a las "acciones municipales o populares", es decir a las que confiere a la "municipalidad y cualquiera persona del pueblo".

41 Sobre el concepto de acción popular véase: Delgado Schneider, Verónica, La protección del Medio Ambiente a través de las acciones populares del artículo 948 del Código Civil de Andrés Bello: un estudio histórico-comparativo, en TAPIA RodríGUEZ, Mauricio - Martinic Galetovic, M. Dora (Editores), Sesquicentenario del Código Civil de Andrés Bello. Pasado, presente y futuro de la codificación (Santiago, LexisNexis, 
aunque no sea un "inmediato interesado" 42 .

Ahora bien, "si el daño [contingente] amenazare solamente a personas determinadas, sólo alguna de éstas podrá interponer la acción”. Ellos son inmediatos interesados.

En las calidades señaladas podrán obrar personas naturales o jurídicas, públicas o privadas.

Cabe precisar que un amenazado directo puede accionar en su propio interés o como un actor popular si es que invoca el interés público en casos de daños contingentes que además de amenazarlo a él directamente amenazaren también a personas indeterminadas. Lo anterior puede tener importancia concretamente en cuanto a los incentivos económicos que establece el artículo 2334 del CC pues éstos se conceden sólo al actor popular.

Es necesario hacer presente que las dos demandas de este tipo que han sido acogidas por nuestros tribunales fueron interpuestas por actores populares $^{43}$ y en una de ellas dicha calidad la invocó una persona jurídica ${ }^{44}$.

\section{Objeto de la condena}

El Código Civil no fija cuál ha de ser el contenido de la condena cuando se acoge una acción por daño contingente del artículo 2333.

Sin embargo, teniendo presente que ésta es de aquellas que busca "precaver un daño" 45 , acogerla conllevará entonces imponer medidas destinadas

2005), T. II, pp. 907-937, donde además hay reproducidas una serie de opiniones doctrinarias que coinciden con lo expuesto, como la de ALESSANDRI R. y SOMARRIVA U., para quienes la acción popular es "aquella que se reconoce a cualquier persona para la defensa de un interés público, y sobre todo a aquellas que, por el hecho que lo contraviene, también han sufrido o pueden sufrir un daño en su interés privado", y la de CASARINO VITERBO para quienes son "aquellas que se hacen valer por cualquier persona del pueblo en el sólo interés de la comunidad".

42 Según se desprende de lo dispuesto en el artículo 949 CC, el cual dispone que "las acciones municipales o populares se entenderán sin perjuicio de las que competan a los inmediatos interesados".

43 Sentencia del 2o Juzgado de Letras en lo Civil de Concepción, de 16 de octubre de 2006, dictada por el Juez Titular don Camilo Álvarez Órdenes, Rol 16752006, caratulada "Sepúlveda Torres y otros con Servicio de la Vivienda y Urbanización Octava Región del Bío Bío"; Corte de Apelaciones de Santiago, sentencia de 27 de febrero de 2015, Rol 7396-2014, caratulada "Sociedad Concesionaria Rutas del Pacífico S.A. con Sociedad Agrícola ARC Holding Ltda.”, redacción de la ministra señora Jessica González Troncoso, caso en el cual accionó una sociedad concesionaria de obras públicas.

${ }^{44}$ Corte de Apelaciones de Santiago, sentencia de 27 de febrero de 2015, Rol 7396-2014, caratulada "Sociedad Concesionaria Rutas del Pacífico S.A. con Sociedad Agrícola ARC Holding Ltda.".

${ }^{45}$ Aludidas expresamente en el inciso 2o del art. 950 del Código Civil. 
a "prevenir un riesgo, daño o peligro, para guardarse de él y evitarlo", toda vez que ello implica, precisamente, "precaver" según el Diccionario de la Real Academia Española de la Lengua.

Para lo anterior, orientativas serán las proposiciones que haga el actor al enunciar en su demanda las peticiones sometidas a la decisión del tribunal (cfr. art. 254 No5 CPC), así como la prueba que hayan podido rendirse al respecto, en especial si entre los hechos sustanciales, pertinentes y controvertidos sobre los que debió versar se incluyeron las medidas adecuadas para prevenir el daño contingente ${ }^{46}$.

En todo caso, será el juez quien en definitiva decretará las medidas que estime conducentes a evitar la producción del daño, imponiendo al efecto obligaciones de hacer o no hacer para el condenado ${ }^{47}$.

$\mathrm{Al}$ respecto, nuestra doctrina señala que al acoger esta acción el juez tendrá una "amplia posibilidad de resolver efectivas e inagotables medidas tendientes a impedir la consumación del daño" 48 , ello pues tales medidas "no están tipificadas en la ley, y serán multiformes dependiendo de la naturaleza del daño y del modo en que está amenazando a la víctima" ${ }^{4}$, señalándose como ejemplos de condenas en este tipo de acciones "la paralización de la obra nueva denunciada, la destrucción o reparación del edificio o construcción ruinosos, la extracción de los árboles mal arraigados, la remoción de la cosa que de la parte superior de un edificio o de otro paraje elevado amenace caída" 50 .

Y en lo que respecta a la jurisprudencia, en las acciones acogidas se han impuesto obligaciones de hacer, como "limpiar y cercar debidamente el inmueble de autos" 51 o "comunicar y registrar ante la autoridad competente-CONAF- y asimismo informar a la demandante, con la anticipación necesaria, la decisión de efectuar "quemas controladas" en el Predio de que se trata, cumpliendo para ello con las formalidades del Decreto Ley

46 Serán importante las opiniones de expertos que puedan obrar en el proceso, en especial tratándose materias técnicas, y que pudieran haberse incorporado como informes periciales, declaraciones de testigos o documentos.

${ }^{47}$ En esta línea, en el caso de la acción popular preventiva otorgada ante la "cosa que, de la parte superior de un edificio o de otro paraje elevado, amenace caída y daño" se señala expresamente que su es objeto "pedir la remoción" de ésta (art. 2328 inciso $2^{\circ}$ ).

${ }^{48}$ Molinari Valdés, cit. (n. 4), p. 213.

49 Corral Talciani, Lecciones, cit. (n. 3), p. 413.

50 Alessandri Rodríguez, cit. (n. 3), p. 219.

${ }^{51}$ Sentencia del $2^{\circ}$ Juzgado de Letras en lo Civil de Concepción, de 16 de octubre de 2006, dictada por el Juez Titular don Camilo Álvarez Órdenes, Rol 16752006, caratulada "Sepúlveda Torres y otros con Servicio de la Vivienda y Urbanización Octava Región del Bío Bío”. 
$\mathrm{N}^{\circ}$ 276, de 1980, del Ministerio de Agricultura" 52 y obligaciones de no hacer, al ordenarse que "se prohíbe todo tipo de acto que implique la quema de cualquier material vegetal, sintético y/o plástico en el predio denominado Paso Tapihue, como mecanismo para regular la temperatura en los viñedos del inmueble, sin perjuicio del ejercicio de los derechos que la legislación vigente reconoce en el Decreto Ley Nº 276, de 1980, del Ministerio de Agricultura" ${ }^{\text {3 }}$.

Finalmente, cabe hacer presente que como aun no hay un daño inferido, sino sólo una amenaza de daño, mal podría pedirse y/o decretarse una reparación in natura o por equivalente (sea o no dinerario) de un daño contingente ${ }^{54}$.

\section{Incentivos económicos para el actor popular}

Nuestro codificador junto con consagrar acciones populares preventivas en el título XXXV del Libro IV buscó incentivar su ejercicio estableciendo en su artículo 2334 que:

"Si las acciones populares a que dan derecho los artículos precedentes parecieren fundadas, será el actor indemnizado de todas las costas de la acción, y se le pagará lo que valgan el tiempo y diligencia empleados en ella, sin perjuicio de la remuneración específica que concede la ley en casos determinados".

El precepto anotado se refiere tanto a la analizada acción popular por daño contingente del artículo 2333 como a la establecida en el artículo

52 Corte de Apelaciones de Santiago, sentencia de 27 de febrero de 2015, Rol 7396-2014, caratulada "Sociedad Concesionaria Rutas del Pacífico S.A. con Sociedad Agrícola ARC Holding Ltda.”, redacción de la ministra señora Jessica González Troncoso.

53 Corte de Apelaciones de Santiago, sentencia de 27 de febrero de 2015, Rol 7396-2014, , caratulada "Sociedad Concesionaria Rutas del Pacífico S.A. con Sociedad Agrícola ARC Holding Ltda.”, redacción de la ministra señora Jessica González Troncoso.

${ }^{54}$ En esta línea, el artículo 946 del Código Civil dado materia de acciones posesoria especiales distingue entre el daño "temido" y el daño "sufrido", asociando al primero las querellas o denuncias dirigidas a la "prohibición, destrucción o enmienda de la obra", en tanto que para el daño "sufrido" o "recibido" admite que se pueda pedir su "indemnización” (cfr. artículo 946).

Impropiamente aparece solicitado el pago de una suma de dinero por daño contingente en las demandas que dieron lugar a sentencias del $2^{\circ}$ Juzgado Civil de Temuco, de 24 de marzo de 2012, dictada por doña Mónica Toledo Reyne, Juez subrogante, Rol 2445- 2011, caratulada "Gacitúa con Municipalidad de Temuco", y a sentencia del $1^{\circ}$ Juzgado Civil de Temuco, de 18 de enero de 2016, dictada por don Javier Bascur Pavéz, Juez Suplente en causa Rol 5675-2014, caratulada "Vega con Municipalidad de Temuco". Aunque dichas peticiones fueron rechazadas. 
2328 inciso segundo ("para pedir la remoción" de la cosa que "de la parte superior de un edificio o de otro paraje elevado, amenace caída y daño"), las cuales, entonces, si "parecieren fundadas" llevan a que el actor deba ser indemnizado: i) de "todas las costas de la acción", es decir, las procesales y personales que tasarán y regularán por el tribunal, y ii) de "lo que valgan el tiempo y diligencia empleados en ella", lo que deberá ser determinado judicialmente en el proceso. Ello "sin perjuicio de la remuneración específica que concede la ley en casos determinados", como acontece en el caso de la acción popular del artículo 948 del $C^{55}$.

Justificando los pagos que impone el artículo 2334 se ha dicho que "en atención al interés público comprometido, se compensa al denunciante el empobrecimiento que sufre en razón de la acción"56.

Cabe hacer presente que en las dos sentencias que han acogido este tipo de acciones han existido pronunciamientos sobre este punto.

$\mathrm{Al}$ efecto, en la primera de ellas el juez fijó a favor de los actores populares una suma de dinero "por concepto de tiempo y diligencias empleados en el ejercicio de la acción", aunque rechazó condenar en costas al demandado pues estimó que "ha tenido motivos plausibles para litigar"57, aspecto este último que parece discutible si se tiene presente que el artículo 2334 exige sólo que las acciones populares "parecieren fundadas", para que imperativamente ("será el actor indemnizado") ordene al juez que indemnice al actor popular con las partidas ahí indicadas, incluyendo las costas, y en este caso la acción había sido acogida.

55 Donde se establece en su inciso $2^{\circ}$ que: "Y siempre que a consecuencia de una acción popular haya de demolerse o enmendarse una construcción, o de resarcirse un daño sufrido, se recompensará al actor, a costa del querellado, con una suma que no baje de la décima, ni exceda a la tercera parte de lo que cueste la demolición o enmienda, o el resarcimiento del daño; sin perjuicio de que si se castiga el delito o negligencia con una pena pecuniaria, se adjudique al actor la mitad".

El artículo 2334 se pudo estar refiriendo además en esta parte al artículo 81 de la Ley sobre organización y atribuciones de las municipalidades de 8 de noviembre de 1854, toda vez que dicha norma, vigente al dictarse el Código Civil, establecía que: "uno o muchos vecinos podrán presentarse ejercitando las acciones de la Municipalidad, dando fianza de responder por las costas del juicio, i de estar a las resoluciones que diere la autoridad judicial. En tales casos la Municipalidad no podrá transijir sin el consentimiento de los que hubieren entablado o sostenido las acciones. En el caso de éxito deberá indemnizarse los gastos a los vecinos que han seguido el juicio $\mathrm{i}$ compensarles sus servicios en proporción al resultado que se hubiere alcanzado" [sic].

56 Barros Bourie, Tratado, cit. (n. 3), p. 874.

57 Sentencia del $2^{\circ}$ Juzgado de Letras en lo Civil de Concepción, de 16 de octubre de 2006, dictada por el Juez Titular don Camilo Álvarez Órdenes, Rol 16752006, caratulada "Sepúlveda Torres y otros con Servicio de la Vivienda y Urbanización Octava Región del Bío Bío”. 
Y en el otro caso condenatorio, citándose el artículo 2334 del CC, se ordenó a los demandados pagar al actor popular "las costas de la causa", aunque sin que expresamente se haya ordenado indemnizarle por lo que "valgan el tiempo y diligencia empleado" en dicha acción, lo que en todo caso está siendo reclamado en fase de cumplimiento ${ }^{58}$.

Finalmente cabe consignar que si se acoge una demanda deducida por un inmediato amenazado que sólo actúa en su propio interés tendrá únicamente derecho al pago de las costas según las reglas generales, mas no a las demás prestaciones que reserva el artículo 2334 al actor popular.

\section{Aspectos procesales}

A diferencia de lo que ocurre con otras acciones destinadas a precaver un daño, establecidas en el Código Civil ${ }^{59}$, no existe para la acción del artículo 2333 un procedimiento específico en nuestro ordenamiento procesal.

Ante ello, y como hemos indicado anteriormente ${ }^{60}$, creemos aplicable a su respecto el juicio sumario, pues por la propia naturaleza de esta acción requiere de una tramitación rápida para ser eficaz en la prevención del daño (artículo 680 inciso $1^{\circ}$ del Código de Procedimiento Civil).

Lo dicho concuerda con lo sostenido por diversos autores ${ }^{61}$ y es también el camino que se siguió en los dos casos de acciones populares acogidas en nuestro país ${ }^{62}$.

Además, a su respecto será posible decretar medidas prejudiciales

58 Corte de Apelaciones de Santiago, sentencia de 27 de febrero de 2015, Rol 7396-2014, caratulada "Sociedad Concesionaria Rutas del Pacífico S.A. con Sociedad Agrícola ARC Holding Ltda.”, redacción de la ministra señora Jessica González Troncoso, apareciendo en el sistema informático del Poder Judicial (www.poderjudicial.cl ) que en fase de cumplimiento incidental el actor solicitó que al tasarse las costas se incluyera "lo que valgan el tiempo y diligencia" empleados en la acción, petición que se encuentra en tramitación al momento de redactar este artículo.

59 Como las acciones posesorias especiales de obra nueva y ruinosa, para las que nuestra legislación contempla un procedimiento especial concentrado (artículos 571 a 576 del Código de Procedimiento Civil, y con referencia expresa incluso a la hipótesis en que accione un actor popular y solicite la recompensa, en el artículo 583 del referido Código).

${ }^{60}$ V. Diez Schwerter - Delgado Schneider, Algunas útiles herramientas..., cit. (n. 1), p. 147.

${ }^{61}$ En tal sentido: Barros Bourie, Tratado, cit. (n. 3), p. 874; Corral talciani, Lecciones, cit. (n. 3), p. 412.

${ }^{62}$ Sentencia de 16 de octubre de 2006, dictada por el Juez Titular del Segundo Juzgado de Letras en lo Civil de Concepción, don Camilo Álvarez Órdenes, Rol 1675-2006, caratulada "Sepúlveda Torres y otros con Servicio de la Vivienda y Urbanización Octava Región del Bío Bío"; Corte de Apelaciones de Santiago, sentencia de 27 de febrero de 2015, Rol 7396-2014, caratulada "Sociedad Concesionaria 
precautorias $^{63}$, las que en todo caso deberán concederse ponderando con detención la limitación a la libertad individual y el grado de anticipación a la condena que puedan implicar ${ }^{64}$.

Respecto de las acciones por daño contingente ambiental que pudieran ejercerse en base al artículo 2333 somos de la idea que no son de competencia de los tribunales ambientales sino de los tribunales civiles desde que la Ley 20.600 de 28.6.2012 le atribuye a los primeros el conocimiento de las "demandas para obtener la reparación del medio ambiente dañado, en conformidad con lo dispuesto en el Título III de la ley No 19.300", es decir aquéllas que parten del presupuesto que ya existe "daño ambiental" el que conforme a esta última ley es "toda pérdida, disminución, detrimento o menoscabo significativo inferido al medio ambiente o a uno o más de sus componentes" (artículo 2 letra e) de la Ley 19.300), pero no una amenaza de daño.

Importante sería en todo caso que nuestro sistema procesal civil regule un procedimiento general de urgencia ${ }^{65}$, así como la intervención expresa de actores populares puesto que ello genera algunos problemas particulares que no tienen actualmente una respuesta técnica precisa, como la compatibilidad o exclusión de distintos actores populares entre sí o con inmediatos amenazados que obren en su propio interés, o la posibilidad de transigir respecto de acciones populares, y los efectos de la cosa juzgada en este caso, entre otros aspectos ${ }^{66}$.

Rutas del Pacífico S.A. con Sociedad Agrícola ARC Holding Ltda.”, redacción de la ministra señora Jessica González Troncoso.

${ }^{63}$ A fin de "evitar la efectiva realización del mal amenazado mientras se ventila el pleito"; Corral Talciani, Lecciones, cit. (n. 3), p. 412.

${ }^{64} \mathrm{Al}$ efecto en una ocasión se rechazó la medida prejudicial precautoria del $\mathrm{N}^{\circ}$ 4 del artículo 290 del CPC consistente específicamente en "Prohibir a toda persona realizar o ejecutar actos que impliquen quema de todo tipo de material sea este vegetal, natural, plástico o artificial en el predio denominado Fundo paso Tapihue, ubicado en el kilómetro 66 de la Ruta 68", considerando para ello el tribunal que "en el evento de decretar la prohibición que se solicita, acarrearía un prejuzgamiento de la cuestión de fondo, conducta que se imputa a la demandada y que sirve de fundamento al líbelo, y trata de satisfacer provisoriamente lo que es materia de definitiva" (así en resolución del $13^{\circ}$ Juzgado Civil de Santiago, de 25 de mayo de 2012, dictada en causa Rol 6954-2012, caratulada "Sociedad Concesionaria Rutas del Pacífico S.A. con Sociedad Agrícola ARC Holding Ltda.” consultable en página del Poder Judicial www.poderjudicial.cl).

${ }^{65}$ En tal sentido: Barros Bourie, Tratado, cit. (n. 3), p. 876.

${ }^{66} \mathrm{Al}$ respecto pueden ser de interés experiencias comparadas, como sucedió en Brasil con la Ley No 4.717, de 29 de junio de 1965 sobre acciones populares, y la Ley 7347 de 24 de junio de 1985; o en Colombia con la Ley 472 de 5 de febrero de 1998, destinada a regular las acciones populares y las acciones de grupo de que 


\section{Prescripción}

Como hemos indicado anteriormente, entendemos que las acciones preventivas del Título XXXV del Libro IV del Código Civil no prescribirán mientras haya justo temor que el daño se produzca ${ }^{67}$ y ello aunque haya transcurrido un lapso más o menos prolongado desde que la amenaza se generó, en la medida que ésta subsista.

Sostenemos lo anterior en el entendido que es inaplicable la regla de prescripción contenida en el artículo 2332 del CC, que alude a las acciones que concede el Título XXXV del Libro IV "por dolo o daño", pues ella está referida a las acciones por un daño ya inferido (respecto de las cuales rigen las acciones reparatorias según establece la cláusula general del artículo 2314 y la mayoría de las normas del Título XXXV del Libro IV del Código Civil) o a las que derivan de dolo (las de los artículos 2316 inciso $2^{\circ}$ y 2317 inciso $2^{\circ}$ ), pero no a las preventivas, por una amenaza de daño (de los artículos 2328, 2333 y 2334), respecto de las que resulta aplicable más propiamente el principio señalado en el artículo 950 inc. $2^{\circ}$ del mismo código, esto es que "las (acciones) dirigidas a precaver un daño no prescriben mientras haya justo motivo de temerlo" 68 .

\section{CONCLUSIONES}

Hecho este análisis concluimos que:

1. Con la original acción general por daño contingente del artículo 2333 del CC el sistema chileno de responsabilidad extracontractual cumple normativamente una función preventiva general, que coexiste junto a la tradicional y conocida función reparatoria por daños inferidos.

2. La acción del artículo 2333 del CC tiene un amplio alcance, pues procederá en todos los casos de daño contingente que por imprudencia o negligencia de alguien amenace a personas determinadas o indeterminadas. En este último caso Bello concede acción popular, atendido el interés público comprometido al existir aquí una amenaza de "daño público". ${ }^{69}$

trata el artículo 88 de la Constitución Política de Colombia; y en el Código Modelo de procesos colectivos para Iberoamérica, propuesto por el Instituto Iberoamericano de Derecho Procesal (Caracas, 2014).

${ }^{67}$ Diez Schwerter - Delgado Schneider, Algunas útiles herramientas, cit. (n. 1), p. 147. En tal sentido: Corral TalCiani, Lecciones, cit. (n. 3), p. 414.

${ }^{68}$ Inclusive el artículo $1110 \mathrm{~d}$ ) inciso $2^{\circ}$ del Proyecto Inédito señalaba que: "Las (acciones) dirigidas a precaver un daño que fundadamente se teme, no prescriben en tiempo alguno".

${ }^{69}$ Sobre la noción de "lo público", entendido como lo que interesa al pueblo (y no aquello estatal), como fundamento de la popularidad ver: Delgado Schneider, Verónica, cit. (n. 41), pp. 917 y 918. 
Además incentiva su ejercicio estableciendo partidas económicas en favor del actor popular si su acción pareciere fundada (artículo 2334).

3. Si bien hasta el momento constatamos una escasa utilización práctica de la acción por daño contingente del artículo 2333 del CC, la situación podría revertirse si existiera un mayor conocimiento de su contenido y alcance por parte de los operadores del derecho, en especial de los abogados litigantes, esperando que esta investigación sea un aporte para ello.

4. La utilización de las acciones populares contribuye a un mayor control del interés público, pues, como bien expresara Sarmiento Palacio analizando los artículos correspondientes del Código Civil colombiano, ellas se traducirán en la práctica en "una vigilancia dual, pública y privada, sobre los intereses generales que hasta ahora fueron depositados solamente al cuidado paternalista de la administración pública"70.

5. En este contexto, sería oportuno que el legislador procesal se hiciera cargo de introducir las reformas necesarias para solucionar adecuadamente los problemas que conlleva el ejercicio de acciones de urgencia, así como la intervención de actores populares, aspectos que hoy deben ser resueltos aplicando procedimientos generales y tradicionales que no los tuvieron presentes.

\section{BibLIOGRAFÍA}

Alessandri Rodríguez, Arturo, De la responsabilidad extracontractual en el Derecho Civil chileno (Santiago, Imprenta Universitaria, 1943), 716 p.

Barros Bourie, Enrique, Tratado de responsabilidad extracontractual (Santiago, Editorial Jurídica de Chile, 2006), 1230 p.

Corral TalCiani, Hernán, Lecciones de responsabilidad civil extracontractual (Santiago, Thomson Reuters, 2013), 475 p.

Delgado Schneider, Verónica, La protección del Medio Ambiente a través de las acciones populares del artículo 948 del Código Civil de Andrés Bello: un estudio histórico-comparativo, en TAPIA Rodríguez, Mauricio - MarTinic G., M. Dora (Editores), Sesquicentenario del Código Civil de Andrés Bello. Pasado, presente y futuro de la codificación (Santiago, LexisNexis, 2005), T. II, pp. 907-937.

Diez SChwerter, José L., Notas sobre la acción preventiva de daños del artículo 2333 del Código Civil: a propósito de un fallo reciente, en Revista de Derecho Universidad de Concepción (Chile), 217-218, 2005 [pero 2006], pp. 317-321.

Diez SCHWERTER, José Luis, La aplicación de la acción por daño contingente en Chile, Colombia y Ecuador: del modelo de Bello a nuestros días, en Revista de Derecho Privado, Universidad Externado de Colombia, 2016, volumen 30, en prensa.

Diez SCHWERTER, José Luis, El daño extracontractual. Jurisprudencia y doctrina (Santiago, Editorial Jurídica de Chile, 1997), 291 p.

70 Sarmiento Palacio, Germán, cit. (n. 38), p. 111. 
Diez Schwerter, José L. y Delgado Schneider, Verónica, Algunas útiles herramientas olvidadas en nuestra práctica del Derecho de Daños, en Revista de Derecho Universidad de Concepción (Chile), 214, 2003 [pero 2005], pp. 143-150.

LARROUCAU TORRES, Jorge, La culpa y el dolo en la responsabilidad extracontractual. Análisis jurisprudencial, Memoria de Prueba, Fondo de Publicaciones, (Facultad de Ciencias Jurídicas y Sociales, Universidad de Concepción, 2005), 242 p.

Meza Barros, Ramón, Manual de Derecho Civil. De las fuentes de las obligaciones (9a edición, actualizada por Pedro Pablo Vergara, Santiago, Editorial Jurídica de Chile, 1997), T. II.

Molinari VAldés, Aldo, De la responsabilidad civil al derecho de daños y tutela preventiva civil (Santiago, LexisNexis, 2004), 247 p.

Pino Silva, Néstor, Responsabilidad preventiva, en Revista de Estudios Ius Novum, 2, 2009, pp. 243-270.

Restrepo Rodríguez, Tomás, El remedio preventivo en la responsabilidad civil, en Revista de Derecho Privado Universidad Externado de Colombia, N 14, 2008, Colombia, pp. 219-238.

Rodríguez Grez, Pablo, Responsabilidad extracontractual (Santiago, Editorial Jurídica de Chile, 1999), 505 p.

Sarmiento Palacio, Germán, Las acciones populares en del Derecho Privado colombiano (reimpresión de la primera edición de 1988, Bogotá, Editorial Universidad del Rosario, 2006), 140 p.

Soтo Kloss, Eduardo, El Recurso de Protección (Santiago, Editorial Jurídica de Chile, 1982), $582 \mathrm{p}$.

Tamayo Jaramillo, Javier, De la responsabilidad civil, (Santa Fe de Bogotá, Ed. Temis, 1986), T. II (De los perjuicios y su indemnización), $1250 \mathrm{p}$.

TAPIA SuÁrez, Orlando, De la responsabilidad civil en general y de la responsabilidad delictual entre los contratantes, Memoria de Prueba, Publicaciones del Seminario de Derecho Privado de la Facultad de Ciencias Jurídicas y Sociales de la Universidad de Concepción (Escuela Tipográfica Salesiana, Concepción, 1941), reimpresión (Santiago, LexisNexis, 2006), 654 p. 
